mạch kết hợp với kẹp trực tiếp hoặc nút mạch) cho kết quả tốt ở thời điểm 12 tháng sau điều trị.

\section{TÀI LIÊU THAM KHẢO}

1. Zijlstra, I.A., et al., Coiling and clipping of middle cerebral artery aneurysms: a systematic review on clinical and imaging outcome. J Neurointerv Surg, 2016. 8(1): p. 24-9.

2. Bonita, R. and R. Beaglehole, Recovery of motor function after stroke. (0039-2499 (Print)).

3. Matsukawa, $\mathbf{H}_{\text {., }}$ et al., Surgical Treatment of Middle Cerebral Artery Aneurysms: Aneurysm Location and Size Ratio as Risk Factors for Neurologic Worsening and Ischemic Complications. World Neurosurg, 2018. 117: p. e563-e570.

4. Elsharkawy, A., et al., A new, more accurate classification of middle cerebral artery aneurysms: computed tomography angiographic study of 1,009 consecutive cases with 1,309 middle cerebral artery aneurysms. Neurosurgery, 2013. 73(1): p. 94-102; discussion 102.
5. Connolly, E.S., Jr., et al., Guidelines for the management of aneurysmal subarachnoid hemorrhage: a guideline for healthcare professionals from the American Heart Association/american Stroke Association. Stroke, 2012. 43(6): p. 1711-37.

6. Dashti, R., et al., Microneurosurgical management of middle cerebral artery bifurcation aneurysms. Surg Neurol, 2007. 67(5): p. 441-56.

7. Jean, W.C., D.R. Felbaum, and H.M. Ngo, How I do it: superficial temporal artery to middle cerebral artery bypass for treatment of giant middle cerebral artery aneurysm. Acta Neurochir (Wien), 2020. 162(3): p. 593-596.

8. Brown, R.D., Jr. and J.P. Broderick Unruptured intracranial aneurysms: epidemiology, natural history, management options, and familial screening. Lancet Neurol, 2014. 13(4): p. 393-404.

9. Chen, S., et al., Hydrocephalus after Subarachnoid Hemorrhage: Pathophysiology, Diagnosis, and Treatment. Biomed Res Int, 2017. 2017: p. 8584753

\title{
KẾT QUẢ ĐIỀU TRI UNG THƯ PHỔI KHÔNG TẾ BÀO NHỎ GIAI ĐOẠN IIIB-IV BẰNG PHÁC ĐỒ PEMETREXED - CISPLATIN
}

\section{TÓM TẮT}

Mục tiêu: Đánh giá kết quả điều trị và độc tính của phác đồ Pemetrexed và Cisplatin trên bệnh nhân ung thư phổi giai đoạn IIIB và IV. Đối tướng và phương pháp: Can thiêp lâm sàng không đối chứng trên 56 bệnh nhân ung thư phổi khống tế bào nhỏ giai đoan IIIB và IV. Kết quả: Sau 06 chu kì đáp ứng một phẩn 22/56 (39,3\%), bênh ổn đinh 26/56 (46,4\%), lợi ích lâm sàng 85,7\%. Có 06 bệnh nhân hạ bạch câuu đồ 3,4 chiếm $10,7 \%$. Thời gian sống thềm không bệnh là $6,1 \pm 3,3$ tháng, thời gian sống thêm toàn bộ là $10,7 \pm 4,1$ tháng. Tý lệ sống thêm 1 năm và 2 năm là $42,4 \%$ và $17,5 \%$. Kết luân: Phác đồ Pemetrexed Cisplatin có hiệu quả và dung nạp tốt trên các bệnh nhân ung thư phổi không tế bào nhó giai đoan di căn xa.

Tư khóa: Ung thư phổi không tế bào nhỏ, đáp ứng một phần, thời gian sống thêm.

\section{SUMMARY}

TREATMENT RESULTS OF STAGE IIIB- IV NON-SMALL CELL LUNG CANCER WITH

PEMETREXED - CISPLATIN REGIMEN

Objects: Evaluating the initial treatment results and toxicity of regimen Pemetrexed and Cisplatin in lung cancer patients at stage IIIB and IV. Subjects

${ }^{1}$ Bệnh viện $74 T W$

${ }^{2}$ Bệnh viện $K$

Chịu trách nhiệm chính: Nguyễn Việt Hà

Email: vietha74@gmail.com

Ngày nhận bài: 26.01.2021

Ngày phản biện khoa học: 22.3.2021

Ngày duyệt bài: 30.3.2021

\section{Nguyễn Việt Hà ${ }^{1}$, Nguyễn Tuyết $\mathrm{Mai}^{2}$}

and Methods: Uncontrolled clinical intervention on 56 lung cancer patients non-small cell at stage IIIB and IV. Results: After 6 cycles: partial response $22 / 56(39,3 \%)$, stable disease $26 / 56(46,4 \%)$, clinical benefits $85,7 \%$. 06 patients drop leukocyte at level 3 and 4 , accounted for $10.7 \%$. Progresive Free Survival $6,1 \pm 3,3$ month , Overall Survival $10,7 \pm 4,1$ month. Survival rates after 1 and 2 year were $42,4 \%$ and $17,5 \%$. Conclusion: Regimen Pemetrexed - Cisplatin was well outcome and tolerated in non-small cell lung cancer patients at distant metastasis stage.

Keywords: Non small cell lung cancer, Partial Response, Survival

\section{I. ĐĂT VẤN ĐỀ}

Ung thư phổi (UTP) là bệnh ác tính của phế quản và phổi, là một trong những loại ung thư phổ biến nhất và là nguyên nhân gây tử vong hàng đầu trong các bệnh ung thư ở nhiều nước trên thế giới cũng như ở Việt Nam. Theo GLOBOCAN năm 2012 trên toàn cầu có khoảng 1,6 triệu người mắc và 1,378 triệu người tử vong do UTP, tương ứng với $13 \%$ tổng số trường hợp mắc và $19,4 \%$ tổng số trường hợp tử vong do tất cả các loại ung thư [1]. Ở Việt Nam theo các số liệu thống kê ghi nhận ung thư giai đoạn 2000 - 2010, UTP đứng hàng đầu ở nam giới với tỷ lệ $35,1 / 100.000$ dân và đứng thứ 3 trong các ung thư ở nữ giới với tỷ lệ 13,9/ 100.000 dân [2].

UTP được phân thành hai nhóm chính là UTP không tế bào nhỏ (UTPKTBN) và UTP tế bào nhỏ 
(UTPTBN), hai nhóm bệnh này khác nhau về đặc điểm bệnh, điều trị và tiên lượng. UTPKTBN chiếm $80-85 \%$ các trường hợp và có tiên lượng tốt hơn UTPTBN[3]. Điêu trị UTPKTBN nói chung phụ thuộc vào giai đoạn bệnh, thể trang chung của người bênh. Có khoảng $40 \%$ bệnh nhân ung thư phổi không phải tế bào nhỏ khi được phát hiện đã có di căn không còn khả năng phẫu thuật hoặc hóa xạ đồng thời. Điều trị toàn thân được áp dụng chủ yếu cho các bệnh nhân này [4].Phác đồ hóa chất đã được khuyến cáo trong điều tri UTPKTBN giai đoạn di căn lan tràn bao gồm cisplatin hoặc carboplatin kết hợp với một trong các thuốc như etoposid, vinblastin, taxan, gemcitabin, vinorelbin. Các phác đồ này mang lại tỷ lệ đáp ứng $17-32 \%$, thời gian sống thêm trung bình 7 đến 10 tháng, tỷ lệ sống thêm 1 năm trung bình khoảng 30-35\% độc tính thường gặp là ức chế tủy xương gây ảnh hưởng tới liều và liệu trình điều trị [5]. Đầu thập ki 21 pemetrexed đã được đưa vào điều trị u trung biểu mô màng phổi [6] và UTPKTBN tiến triển [7]. Pemetrexed là thuốc kháng folate có một nhân pyrolopyrimidine duy nhất và ức chế nhiều enzym phụ thuộc folate, có phổ kháng u rộng hơn so với các thuốc cùng nhóm[8]. Pemetrexed được chứng minh có lợi thế về thời gian sống thêm cho bệnh nhân ung thư phổi không tế bào nhỏ giai đoạn di căn lan tràn. Các phân tích cho thấy hiệu quả vượt trội hơn của pemetrexed trên bệnh nhân không phải tế bào vẩy và là bệnh nhân Á Đông với các dữ liệu về an toàn thuận lợi so với các phương án điểu trị chuẩn khác. Kểt quả của một số thử nghiệm đã cho thấy sự kết hợp của pemetrexed với cisplatin có xu hướng hiệu quả hơn ở các phân nhóm mô học không tế bào vảy về tỷ lệ đáp ứng và thời gian sống thêm. Scagliotti và cộng sự. trong một thử nghiệm pha III cho thấy sự kết hợp cisplatin và pemetrexed không thua kém sự kểt hợp cisplatin và gemcitabine trong NSCLC di căn. Phân tích dưới nhóm của thử nghiệm dựa trên loại mô học đã chứng minh cisplatin và pemetrexed ở bệnh nhân ung thư biểu mô tuyến có thời gian sống them tốt hơn đáng kể so với cisplatin và gemcitabine. Có rất ít nghiên cứu tại Việt nam về phác đồ này. Do đó, nghiên cứu này được thực hiện để đánh giá hiệu quả và tính an toàn của sự kết hợp Pemetrexed và Cisplatin ở bệnh nhân ung thư phổi không tế bào nhỏ không vảy giai đoạn tiến triển.

\section{II. ĐỐI TƯợNG VÀ PHƯƠNG PHÁP NGHIÊN CỨU \\ 2.1. Đối tượng nghiên cứu. Gồm 56 bệnh}

nhân được chẩn đoán ung thư phổi không tế bào nhỏ giai đoạn IIIB - IV được điều trị bằng hoá chất phác đồ Pemetrexed - Cisplatin từ tháng 1/2014 đến tháng 5 / 2017 tại Bệnh viện K

\section{Tiêu chuẩn lứa chọn:}

- Chẩn đoán giai đoạn IIIB-IV theo IASLC 2015

- Mô bệnh học là ung thư phổi không tế bào nhỏ

- Chỉ số toàn trạng (PS) theo thang điểm ECOG (PS 0 - 1)

- Không có chống chỉ định hóa chất

- Đồng ý tham gia nghiên cứu.

- Có hồ sơ ghi nhân thông tin đầy đủ.

\section{Tiêu chuân loai trừ:}

- Bệnh nhân dị ứng với một trong các thành phần của thuốc

- Mô bệnh học là biểu mô vảy hoặc thể hỗn hợp tế bào lớn/nhỏ

- Bệnh nhân bỏ điều trị không phải vì lý do chuyên môn

\subsection{Phương pháp nghiên cứu:}

Thiết kế nghiên cứu: Can thiệp lâm sàng không đối chứng có theo dõi dọc

\section{Các bước tiến hành:}

*Các bệnh nhân đều được đăng kí theo mẫu bệnh án nghiên cứu. Khám đánh giá lâm sàng, cận lâm sàng trước điều trị. Phân loại Mô bệnh học theo bảng phân loại Mô bệnh học các khối u phổi và màng phổi, tim của Tổ chức Y tế thế giới WHO 2015. Phân loại giai đoạn theo IASLC 2015. Đánh giá thang điểm toàn trạng theo thang điểm ECOG (PS).

*Điêu trị hóa chất theo phác đồ: Pemetrexed

\section{- Cisplatin}

\section{Chuẩn bị trước khi truyền}

- Acid Folic $500 \mathrm{mcrg} / \mathrm{ngày}$ uống 7 ngày trước khi truyền liều đầu tiên và uống liên tục hàng ngày trong suốt quá trình điều trị và tiếp tục 21 ngày sau khi kết thúc điều trị

- Vitamin $B_{12} 1000 \mathrm{mcg}$ tiêm bắp một liều trước truyền hóa chất 7 ngày, mỗi 3 tuần.

Hóa chất: Pemetrexed $500 \mathrm{mg} / \mathrm{m}^{2}$ và Cisplatin $75 \mathrm{mg} / \mathrm{m}^{2}$ truyền tĩnh mạch chu kì 21 ngày.

Đánh giá đáp ứng điểu trị sau mỗi 3 đợt hoặc khi bênh nhân có triệu chứng bất thường

Đánh giá đáp ứng thực thể theo tiêu chuẩn RECIST; Đánh giá thời gian sống thêm không bệnh và sống thêm toàn bộ

Đánh giá tác dụng phụ theo WHO.

Xử lý số liệu: Nhập và xử lý số liệu bằng phần mềm SPSS 16.0

\section{KẾT QUẢ NGHIÊN CỨU}

\section{1. Đặc điểm chung của đối tượng} nghiên cứu 
Bảng 1. Đặc điểm chung của đôi tượng nghiên cứu

\begin{tabular}{|c|c|c|}
\hline Đăc điếm & Số BN & $\%$ \\
\hline \multicolumn{3}{|l|}{ Tuối } \\
\hline Trung bình & \multicolumn{2}{|c|}{$57,5 \pm 10,99$} \\
\hline Tuối $<60$ tuối & 30 & 53,6 \\
\hline Tuối $\geq 60$ tuối & 26 & 46,4 \\
\hline \multicolumn{3}{|l|}{ Giới } \\
\hline Nam & 41 & 73,2 \\
\hline Nữ & 15 & 26,8 \\
\hline \multicolumn{3}{|l|}{ Tình trạng hút thuốc } \\
\hline Có hút thuốc lá & 34 & 60,7 \\
\hline Không hút thuốc & 22 & 39,3 \\
\hline \multicolumn{3}{|l|}{ Giai đoạn bệnh } \\
\hline Giai đoạn IIIB & 9 & 16,1 \\
\hline Giai đoạn IV & 47 & 83,9 \\
\hline \multicolumn{3}{|l|}{ Thế trạng chung ECOG } \\
\hline 0 & 19 & 33,9 \\
\hline 1 & 37 & 66,1 \\
\hline
\end{tabular}

Nhận xét: Tuối trung bình: $57,5 \pm 10,99$. Tỳ lệ nam/nữ: 2.7/1.Tuổi thấp nhất: 26 tuổi, tuổi cao nhất: 75 tuổi. Tỷ lệ bệnh nhân hút thuốc lá là $60,7 \%$. Giai đoan IV chiểm đa số 83,9\%.

\subsection{Kết quả điêu trị}

\section{Bảng 2. Số chu ki hóa chất}

\begin{tabular}{|c|c|c|}
\hline Số chu kì & $\begin{array}{c}\text { Số bệnh nhân } \\
(\mathbf{n = 5 6 )}\end{array}$ & Tỷ lệ \% \\
\hline 2 & 3 & 5.4 \\
\hline 3 & 8 & 14.3 \\
\hline 4 & 6 & 10.7 \\
\hline 5 & 5 & 8.9 \\
\hline 6 & 34 & 60.7 \\
\hline Tống số chu kì & \multicolumn{2}{|c|}{283} \\
\hline Số chu kì trung bình & \multicolumn{2}{|c|}{$5,05 \pm 1,3$} \\
\hline
\end{tabular}

Nhân xét: Tống số chu kì hóa chất là 283 lượt, số chu kì trung bình $5,05 \pm 1,3$, số bệnh nhân hóa trị đủ 06 chu kì chiếm tỷ lệ cao 60,7\%.

\section{Bảng 3. Đáp ứng thực thê}

Thời gian Sau 03 chu kì Sau 06 chu kì

\begin{tabular}{|c|c|c|c|c|}
\cline { 2 - 5 } Dáp ứng & $\mathbf{S L}$ & $\mathbf{\%}$ & $\mathbf{S L}$ & $\mathbf{\%}$ \\
\hline Hoàn toàn & 0 & 0 & 0 & 0 \\
\hline Một phần & 24 & 42,9 & 21 & 37,5 \\
\hline Ốn định & 26 & 46,4 & 26 & 46,4 \\
\hline Tiến triển & 6 & 10,7 & 9 & 16,1 \\
\hline Tống & $\mathbf{5 6}$ & $\mathbf{1 0 0}$ & $\mathbf{5 6}$ & $\mathbf{1 0 0}$ \\
\hline $\begin{array}{c}\text { Lợi ích lâm } \\
\text { sàng }\end{array}$ & \multicolumn{2}{|c|}{$89,3 \%$} & \multicolumn{2}{|c|}{$83,9 \%$} \\
\hline
\end{tabular}

Nhận xét: Bệnh đáp ứng một phần sau 03 chu kì là 42,9\%; sau 06 chu kì là 39,3\%; không có bệnh nhân nào đáp ứng hoàn toàn. Tỷ lệ bệnh giữ nguyên sau 03 chu kì và 06 chu kì là 46,4\%. Lợi ích lâm sàng sau 03 chu kì là 89,3\%; sau 06 chu kì là $85,7 \%$.

Bảng 4. Tác dụng phụ của thuốc trên hệ tạo huyêt

\begin{tabular}{|c|c|c|c|c|c|}
\hline Độc tính & Độ I & Độ II & Độ IIIĐộ IV & Tống \\
\hline $\begin{array}{c}\text { Thiếu } \\
\text { máu }\end{array}$ & 16 & 5 & 4 & 0 & $\begin{array}{c}26 / 56 \\
(46,4 \%)\end{array}$ \\
\hline $\begin{array}{c}\text { Hạ } \\
\text { bạch cầu }\end{array}$ & 8 & 4 & 4 & 2 & $\begin{array}{c}18 / 56 \\
(32,1 \%)\end{array}$ \\
\hline $\begin{array}{c}\text { Hạ tiếu } \\
\text { câuu }\end{array}$ & 4 & 0 & 3 & 0 & $\begin{array}{c}7 / 56 \\
(12,5 \%)\end{array}$ \\
\hline
\end{tabular}

Nhận xét: Tác dụng phụ trên hệ tạo huyết chủ yếu độ I,II. Có $04(7,1 \%)$ bệnh nhân thiếu máu độ 3, có $06(10,7 \%)$ bệnh nhân hạ bạch câuu độ 3 và 4 nhưng không có sốt, các bểnh nhân hồi phục tốt sau khi dùng thuốc kích thích tăng sinh bạch câuu. 3 bệnh nhân hạ tiểu câu độ $3(5,3 \%)$.

Bảng 5. Tác dụng phụ của thuốc ngoài hê tao huyêt

\begin{tabular}{|c|c|c|c|c|c|}
\hline Độc tính & $\begin{array}{c}\text { Độ } \\
\text { I }\end{array}$ & $\begin{array}{c}\text { Đồ } \\
\text { Ii }\end{array}$ & $\begin{array}{c}\text { Đố } \\
\text { III }\end{array}$ & $\begin{array}{c}\text { Độ } \\
\text { IV }\end{array}$ & Tổng \\
\hline Tăng Ure & 2 & 0 & 0 & 0 & $2 / 56(3,6 \%)$ \\
\hline Tăng Creatinin & 4 & 0 & 0 & 0 & $4 / 56(7,1 \%)$ \\
\hline Tăng & 4 & 0 & 0 & 0 & $4 / 56(7,1 \%)$ \\
SGOT/SGPT & & & & & \\
\hline Nôn & 10 & 10 & 6 & 0 & $26 / 56(46,4 \%)$ \\
\hline Tiêu chảy & 4 & 0 & 0 & 0 & $4 / 56(7,1 \%)$ \\
\hline Mệt mỏi & 4 & 10 & 0 & 0 & $14 / 56(28,6 \%)$ \\
\hline Sốt & 0 & 2 & 0 & 0 & $2 / 56(3,6 \%)$ \\
\hline
\end{tabular}

Nhân xét: Các tác dung phụ ngoài hệ tạo huyêt chỉ gặp ở mức độ nhẹ.

\section{BÀN LUÂN}

4.1. Về đặc điểm nhóm bệnh nhân. Các bệnh nhân trong nghiên cứu của chúng tôi có độ tuổi trung bình 57,5 ; tỷ lệ nữ $26,8 \%$. Đa số các bệnh nhân ở giai đoạn IV: $83.9 \%$. Tất cả các bệnh nhân đều thuộc typs mô bệnh ung thư biểu mô tuyến, tỷ lệ không có đột biến EGFR là $78,6 \%$. Nghiên cứu của Scagliotti G.V và cS (2008) cho thây tuổi trung bình 61,1 tuổi, tỷ lệ nữ $29,8 \%$; giai đoạn IV là $76,2 \%$. Shepherd $F A$ và cs (2001) nghiên cứu trên 31 bệnh nhân ung thư phổi không tế bào nhỏ điều trị phác đồ Pemetrexed- Cisplatin có độ tuổi trung bình 60 tuổi, tỷ lệ nữ 35,5\%; giai đoạn IV là 83,8\%[7]. Như vậy về tỷ lệ nữ và giai đoạn IV trong nghiên cứu của chúng tôi cũng gần tương đương với các tác giả tuy nhiên về độ tuổi trung bình lại thấp hơn có thể là do tuổi thọ trung bình của các nước phát triển cao hơn người Việt Nam.

Tỳ lệ hút thuốc trong nghiên cứu của chúng tôi là $60,7 \%$ thấp hơn so với nghiên cứu của của Scagliotti G.V (73\%) nhưng cao hơn so với nghiên cứu của Shepherd FA (50,6\%)[7].

4.2. Về phương pháp điêuu trị. Pemetrexed là thuốc chống ung thư kháng folat có tác dụng 
nhờ phá võ̃ các quá trình chuyển hóa chủ yếu phụ thuộc folat cần thiết cho sự sao chép tế bào. So với các thuốc kháng folate khác, pemetrexed có một nhân pyrolopyrimidine duy nhất và ức chế nhiều enzym phụ thuộc folate. Pemetrexed có ái tính gắn kết cao với thụ thể - a1 của folate và khi vào trong tế bào, nó được chuyển đổi nhanh chóng thành các dẫn xuất polyglutamate hoat động. Qúa trình đa glutamat hóa kéo dài sự giữ lại pemetrexed trong tế bào và làm tăng sự tương tác của pemetrexed với thymidate synthase và các enzym mục tiêu phụ thuộc folate khác.

Pemetrexed cho thãy hoạt tính kháng u mạnh trong các nghiên cứu pha III trên u trung biểu mô màng phổi ác tính [6]. Tỷ lệ độc tính huyết học nghiêm trong được quan sát trong giai đoạn đầu nghiên cứu pemetrexed do thuốc liên kết với mức homocysteine huyết thanh (giảm folate và B12). Vì vậy tất cả các bệnh nhân được điều trị pemetrexed được bổ sung axit folic và vitamin B 12 và kết quả cho thấy phương pháp này cải thiện đáng kể độ an toàn của pemetrexed. Sử dung Pemetrexed đơn trị hoặc kết hợp đều có hoạt tính ở cả điều trị bước một và bước hai trong UTPKTBN.

Nghiên cứu của chúng tôi đã thực hiện tổng cộng 283 chu kì hóa trị, số chu kì trung bình là 5,05 (từ $2-6$ chu kì), có 06 chu kì giảm liều do hạ bạch cầu, có 04 bệnh nhân bệnh tiến triển sau 02 chu kì hóa trị được chuyển phác đồ và đưa vào đánh giá độc tính.

4.3. Về kết quả điêu trị. Nghiên cứu của chúng tôi không có bệnh nhân nào đáp ứng hoàn toàn, ghi nhận này cũng phù hợp với y văn thế giới và kết quả thu được từ các thử nghiệm lâm sàng như JMBD, LUX- LUNG3,Shepherd FA. Trong nghiên cứu của chúng tôi tỷ lệ đáp ứng một phần sau 06 chu kì là 37,5\%, tỷ lệ bệnh giữ nguyên là 46,4\%.

Thử nghiệm JMDB so sánh hai phác đồ Pemetrexed - Cisplatin và Gemcitabine - Cisplatin cho tỷ lệ đáp ứng ở nhóm Pem/Cis là $30,6 \%$ trên quần thể bệnh nhân UTPKTBN bao gồm cả ung thư biểu mồ tế bào vảy.

Shepherd FA và cs nghiên cứu điều trị trên 31 bệnh nhân UTPKTBN giai đoạn IIIB và IV bằng phác đồ Pemetrexed - Cisplatin. Tỷ lệ đáp ứng một phần 44,8\% (95\% CI: 26 - 64\%)[7].

Thử nghiệm LUX - Lung 3 được thực hiện trên 345 bệnh nhân UTPKTBN có đột biến EGFR dương tính, đối với các bệnh nhân này các thuốc TKI có hiệu quả rất cao, tuy nhiên với nhóm điều trị phác đồ Pemetrexed- Cisplatin cũng cho một tỷ lệ đáp ứng tổng thể khá cao 44,3\%.

Trong giai đoạn muộn ổn định bệnh cũng là một mục tiêu của điều trị, vì vậy hiệu quả của thuốc được tính trên lợi ích lầm sàng. Trong nghiên cứu của chúng tôi lợi ích lâm sàng sau 03 chu kì là $89,3 \%$; sau 06 chu kì là $83,9 \%$.

\subsection{Về tác dụng phụ}

Tác dung phù trên hệ tạo huyêt. Các nghiên cứu có điều trị bổ sung đầy đủ acid folic và vitamin $B 12$ đều cho thấy các tác dụng trên huyết học độ 3, 4 rất ít gặp. Trong nghiên cứu của chúng tồi có $18 / 56(32,1 \%)$ bệnh nhân hạ bạch cầu các mức độ trong đó có $6 / 56(10,7 \%)$ bệnh nhân hạ bạch cầu độ 3 và 4 . Thiếu máu các mức độ gặp ở 25/56 (46,4\%) bệnh nhân trong đó có $4 / 56(7,1 \%)$ thiếu máu độ 3 , một bênh nhân phải truyền máu, bệnh nhân này có bệnh Thalasemia phối hợp. Có 03 (5,3\%) trường hợp hạ tiểu cầu độ 3 , có 4 bệnh nhân hạ tiểu cầu nhẹ.

Nghiên cứu JMDB cho thấy các tác dụng phụ độ 3,4 trên hệ tạo huyết liên quan đến thuốc cũ̉ng rất thấp: hạ bạch cầu $4,8 \%$, thiếu máu: 5 , $6 \%$, hạ tiểu cầu: $4,1 \%$. Tỷ lệ các độc tính huyết học độ 3 và 4 trong nghiên cứu của Schuette W.H và cs bao gồm giảm bạch cầu $11(16,9 \%)$, thiếu máu $5(7,7 \%)$, giảm tiểu cầu $2(3.1 \%)$.

Như vậy các tác dụng phụ trên hệ tạo huyết ở các nghiên cứu cũng gần tương đương với nghiên cứu của chúng tôi.

Tác dụng phụ ngoài hệ tạo huyêt. Trong nghiên cứu của chúng tôi chỉ có $4 / 56(7,1 \%)$ bệnh nhân tăng men gan độ $1,6 / 56(10,7 \%)$ bệnh nhân tăng Urê và creatinin độ 1 , các bệnh nhân hồi phục tốt không cần giảm liều điều trị. Nôn các mức độ xảy ra ở 26/56 (46,4\%) bệnh nhân trong đó nôn mức độ 3 gặp ở 6/56 (10,7\%) bệnh nhân, không có bệnh nhân nào tiêu chảy trầm trọng, có $16 / 56(28,6 \%)$ bệnh nhân mệt mỏi nhưng hồi phục tốt sau khi nghỉ ngơi và không phải kéo dài thời gian điều trị. Có 2 bệnh nhân sốt không liên quan đến hạ bạch cầu và bệnh nhân đáp ứng tốt với điều trị triệu chứng. Các tác dụng phụ ngoài hệ tạo huyết trong nghiên cứu của chúng tôi ghi nhận được cũng gần tương đương với các tác giả khác trên thế giới.

Trong nghiên cứu JMDB ghi nhân các tác dụng phụ mức độ 3 và 4 gồm có nôn và buồn nôn: $13,3 \%$; mệt mỏi: $6,7 \%$; rụng tóc $11,9 \%$

Nghiên cứu của Shepherd chỉ có $2 / 31(6,5 \%)$ bệnh nhân buồn nôn mức độ $3,3 / 31(9,7 \%)$ bệnh nhân tiêu chảy mức độ 3 và 4 , có một bệnh nhân sốt do hạ bạch cầu. 
Nghiên cứu LUX-Lung 3 các tác dung phụ ghi nhận ở nhóm Pem/cis gồm: nôn các mức độ: 42,3\%; độ 3 và 4: 2,6\%; mệt mỏi các mức độ: $46,8 \%$; tiểu chảy độ 1 và 2 là $15,3 \%$.

Nghiên cứu của Schuette W.H ghi nhận buồn nôn chỉ có 3 (4.6\%) bệnh nhân

\section{KẾT LUÂNN}

5.1. Kểi quả điêu trị. Tỷ lệ đáp ứng một phần 37,5\%; bệnh ổn định 46,4\%. Lợi ích lâm sàng sau 06 chu kì 83,9\%.

5.2. Tác dụng phụ của thuốc. Tác dụng phụ trên hệ tạo huyết mức độ 3 và 4 gặp: hạ bạch cầu 10,7\%; thiếu máu $7,1 \%$; hạ tiểu cầu $5,3 \%$. Tác dụng phụ ngoài hệ tạo huyết mức độ 3 và 4 chỉ gặp nôn: $10,7 \%$.

Như vâyy phác đồ Pemetrexed - Cisplatin có hiệu quả và dung nạp rất tốt trên các bệnh nhân ung thư phổi giai đoạn muộn.

\section{TÀI LIÊU THAM KHẢO}

1. GLOBOCAN (2012), "Etimated Cancer Incidence, Mortality and Prevalance Worldwide in 2012".

2. Bùi Diệu, Nguyễn Bá Đức, Trân Văn Thuấn, Nguyến Thị Hoài Nga và cs (2012), "Gánh nậng bệnh ung thư và chiến lược phòng chống ung thư quốc gia đến năm 2020", Tạp chí Ung thư hoc Viêt Nam, số 1 tr $13-19$.

3. Nguyển Bá Đức (2007), "Chẩn đoán và điều trị bệnh ung thu", Nhà xuất bản y hoc tr. $176-187$.

4. Van Houtte $P$, McDonald $S$, Yuang-Chi Chang A, Salazar OM. Lung cancer 8 ed. In: Rubin P, Williams JP, editors. Clinical oncology: a multidisciplinary approach for physicians and students. Philadelphia, PA: WB Saunders Company; 2001

5. Schiller, J.H., et al., Comparison of four chemotherapy regimens for advanced non-small-cell lung cancer. N Engl J Med, 2002. 346(2): p. 92-8.

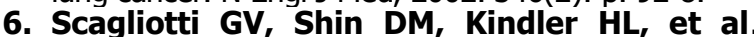
Phase II study of pemetrexed with and without folic acid and vitamin B 12 as front-line therapy in malignant pleural mesothelioma. J Clin Oncol 2003; 21: $1556-61$

7. Shepherd FA, Dancey J, Arnold A, et al. Phase II study of pemetrexed disodium, a multitargeted antifolate, and cisplatin as first-line therapy in patients with advanced non-small cell lung carcinoma. Cancer 2001 ; 92: $595-600$.

8. Goldman DI, Zhao R. Molecular, biochemical, and cellular pharmacology of pemetrexed. Semin Oncol 2002;29:3-17

9. Zinner RG, Obasaju CK, Fossella FV, et al. A phase II trial of ALIMTA plus carboplatin (AC) in patients (pts) with advanced non-small-cell lung cancer (NSCLC) [abstract P-522]. Lung Cancer 2003 ; 41: S223

\section{NGHIÊN CỨU ĐĂC ĐIỂM LÂM SÀNG, CÂN LÂM SÀNG CỦA UNG THƯ BÀNG QUANG TẠI BỆNH VIỆN K}

\section{TÓM TẮT}

Mục tiêu: Nghiên cứu đặc điểm lâm sàng, cận lâm sàng của bệnh nhân ung thư bàng quang. Đối tượng và phướng pháp nghiên cứu: Nghiển cứu can thiệp lâm sàng không đối chứng tiến hành trên các bệnh nhân ung thư biểu mổ bàng quang đã được phẩu thuật cắt bàng quang toàn bộ và chuyển lưu dòng tiểu tại Bệnh viện $K$. Kết quả: Đa số các bênh nhân là nam giới trong độ tuổi 50-70; 14 bệnh nhân từng có tiền sử mổ nội soi cắt u và mổ cắt bán phần bàng quang. 77,4\% bệnh nhân được phấu thuật nội soi chẩn đoán giai đoạn trước mổ.Bệnh nhân nghiện thuốc lá $(80,6 \%)$ và nghiên rươu $(64,5 \%)$. Đái máu là triệu chứng lâm sàng chủ yếu $(80,6 \%)$ Tồng phân tích nước tiểu: $90,3 \%$ hồng câu niêu, $71 \%$ có bach cầu niệu, $71 \%$ có protein niệu. Bệnh nhân có tổn thương u đớn độc 61,3\%; kích thước u từ 3-5 cm. Vị trí u hay

\section{*Bênh viện K}

Chiu trách nhiệm chính: Phạm Văn Bình

Email: binhva@yahoo.fr

Ngày nhận bài: 22.01.2021

Ngày phản biên khoa học: 19.3.2021

Ngày duyệt bài: 26.3.2021
Phạm Văn Bình*, Đỗ Anh Tuấn*

găp nhiêu vị trí $29 \%$; thành bên và thành sau tương đương nhau 22,6\%; thành trước $16,1 \%$ và có 3 trường hợp $9,7 \%$ u chèn ép lỗ niệu quản gây giãn thân. Gia đoan U: T2 58,2\%, T3 chiếm $19,4 \%$ và T4 chiếm $6,5 \%$. Bệnh nhân giai đoạn II $77,4 \%$. Giải phẫu bênh ung thư biểu mô chuyển tiếp 96,8\%. Kết luân: Ung thư bàng quang hay gặp ở nam hơn ở nữ, hút thuốc lá và nghiện rượu là yếu tố nguy cơ cao, đái máu là dấu hiệu lâm sàng phổ biến, giải phẫu bệnh chủ yếu là ung thư biểu mô chuyển tiếp

Tư khóa: Ung thư bàng quang.

\section{SUMMARY}

STUDY OF CLINICAL AND SUBCLINICAL FEATURES OF BLADDER CANCER IN K HOSPITAL

Purpose: To study clinical and subclinical features of bladder cancer patients. Objects and methods: An uncontrolled clinical intervention study was conducted on bladder cancer patients who had a total bladder resection at $\mathrm{K}$ Hospital. Results: Almost patients were men between the ages of $50-70 ; 14$ patients had a history of laparoscopy to remove tumors and partial bladder surgery, of which 2 patients had a history of laparoscopic surgery to remove the tumor and then the bladdectomy 